\title{
Ultrafast CMR to deliver high volume screening of an at risk thalassemia population in the developing world: preliminary results from the TIC-TOC study (Thailand and UK international collaboration in thalassaemia using an optimised ultrafast CMR protocol)
}

\author{
Amna Abdel-Gadir ${ }^{1,2^{*}}$, Yongkasem Vorasettakarnkij ${ }^{3}$, Hataichanok Ngamkasem ${ }^{3}$, Sabrina Nordin², \\ Emmanuel O Ako ${ }^{1,2}$, Monravee Tumkosit ${ }^{3}$, Pranee Sutcharitchan ${ }^{3}$, Peter Kellman ${ }^{4}$, Stefan K Piechnik ${ }^{5}$, \\ Juliano L Fernandes ${ }^{6}$, Mark Westwood ${ }^{2}$, John Porter ${ }^{7}$, John Malcolm Walker ${ }^{1}$, James Moon ${ }^{2,1}$ \\ From 19th Annual SCMR Scientific Sessions \\ Los Angeles, CA, USA. 27-30 January 2016
}

\section{Background}

The vast majority $(>100,000)$ of thalassemia patients at risk of iron overload live in countries with limited red cell transfusions and chelating agents, with serum ferritin used as the method for iron monitoring. Cardiac iron can cause heart failure, but iron detection using CMR is perceived as expensive, time consuming and difficult. Parametric mapping (T2* or T1) can be fast and allows instant recognition of iron loading.

We aimed to perform CMR in the developing world to quantify cardiac and liver iron, assessing its speed, cost, reliability, and clinical information yield.

\section{Methods}

In a leading government hospital in Bangkok, Thailand we set up an ultrafast mapping protocol and analysis pipeline. In 2 days, 128 scans were performed in 97 thalassaemia patients and 11 healthy volunteers. The protocol consisted of: localisers, HASTE, pilots, $\mathrm{T} 2 *$ and T1 maps (figure 1a,b,c,d), and 2 and 4 chamber cines. A short axis stack was also acquired if there was evidence of impairment on long axis cine imaging. Maps were analysed immediately and off-line (truth standard). Repeatability was performed in 20 (10 patients and

${ }^{1}$ Institute of Cardiovascular Science, University College London, London, UK Full list of author information is available at the end of the article
10 healthy volunteers). Thalassemia subtype, transfusion and past medical history, mean and same day ferritin levels served as comparators.

\section{Results}

Baseline patient characteristics are shown in table 1 . The mean patient age was $34 \pm 12$ (70\% female). 64 scans per day were performed with a mean of 6 patients per hour, and $8.3 \pm 2.4$ minutes per scan. Analysis of T1 and $\mathrm{T}^{*}$ maps was completed within 1 minute of last image acquisition. $91 \%$ of patients had liver iron by $\mathrm{T} 2$ \% comprising of 41 (42\%) with severe loading, 29 (30\%) moderate, 18 (19\%) mild, and 9 (9\%) undetectable. 15 (16\%) of patients had cardiac iron by T2*: 3 mild, 2 moderate, and 10 severe. Instant analysis of $\mathrm{T} 1$ and $\mathrm{T} 2$ * maps was robust with high concordance with traditional off-line analysis. In the heart, T1 mapping agreed with $\mathrm{T} 2 *$ with excellent correlation (T2* vs myocardial ShMOLLI $\mathrm{r}=0.885$; vs MOLLI $\mathrm{r}=0.875$, both $\mathrm{p}<$ $0.0001)$. However, $24 \%(23)$ additional patients had normal myocardial $\mathrm{T}^{*}$ but low $\mathrm{T} 1$ values, suggesting missed iron. In the liver, T1 mapping agreed with T2* (ShMOLLI $\mathrm{r}=0.598$; MOLLI $\mathrm{r}=0.582$, both $\mathrm{p}<$ $0.0001)$, and correlated with mean ferritins $(\mathrm{p}<0.005)$. T1 mapping had higher correlation with ferritin than 

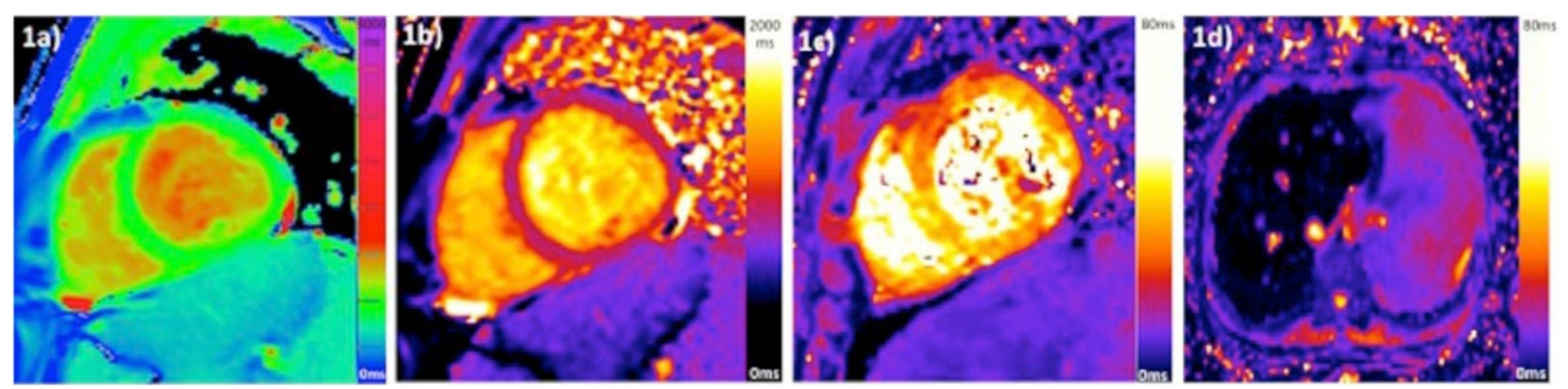

Figure 1 T1 and T2* maps acquired. 1a) myocardial ShMOLLI; 1b) myocardial MOLLl; 1c) myocardial T2*; 1 d) liver T2*. Liver T1 values were obtained from the short axis views

Table 1 Patient baseline characteristics.

\begin{tabular}{cc}
\hline $\mathbf{N}$ & $\mathbf{9 7}$ \\
\hline Male/ Female & $31 / 66$ \\
Age (years) & $34.1 \pm 12.1$ \\
Thalassemia subtype (\%) & \\
Thal/ HbE & 60 \\
Thalassemia intermedia & 29 \\
Thalassemia major & 11 \\
Transfusion history (\%) & \\
None & 4 \\
Less than 8 units/yr & 4 \\
Greater than 8 units/yr & 92 \\
Hb (g/dL) & $8.05 \pm 1.24$ \\
Ferritin (ug/L) & $3533 \pm 2897$ \\
Scan duration (mins) & $8.3 \pm 2.4$ \\
\hline
\end{tabular}

$\mathrm{T} 2 \%$, particularly in severe patients. However, in most patients the $\mathrm{T} 2 \%$ curves were censored to just 2 points.

\section{Conclusions}

Ultrafast CMR in the developing world using parametric mapping for iron overload is possible. We have demonstrated that 60 scans a day at 8 minutes per scan is achieveable. A follow-up study and pilot clinical service is underway.

\section{Authors' details}

${ }^{1}$ Institute of Cardiovascular Science, University College London, London, UK. ${ }^{2}$ Barts Heart Centre, London, UK. ${ }^{3}$ Chulalongkorn University, Bangkok, UK. ${ }^{4} \mathrm{NIH}$, Bethesda, MD, USA. ${ }^{5}$ University of Oxford, Oxford, UK. ${ }^{6}$ Jose Michel Kalaf Research Institute, Sao Paulo, Brazil. ${ }^{7}$ Haematology, University College London, London, UK.

Published: 27 January 2016
doi:10.1186/1532-429X-18-S1-039

Cite this article as: Abdel-Gadir et al:: Ultrafast CMR to deliver high volume screening of an at risk thalassemia population in the developing world: preliminary results from the TIC-TOC study (Thailand and UK international collaboration in thalassaemia using an optimised ultrafast CMR protocol). Journal of Cardiovascular Magnetic Resonance 2016 18(Suppl 1):039.

\section{Submit your next manuscript to BioMed Central and take full advantage of:}

- Convenient online submission

- Thorough peer review

- No space constraints or color figure charges

- Immediate publication on acceptance

- Inclusion in PubMed, CAS, Scopus and Google Scholar

- Research which is freely available for redistribution 